\title{
Height-Diameter Relationships for Jack Pine Seedlots of Different Genetic Improvement Levels
}

\author{
By Y. H. WenG ${ }^{\left.1), 2),{ }^{*}\right)}$, J. KershaW ${ }^{2)}$, K. Tosh ${ }^{1)}$, G. AdAms ${ }^{3)}$ and M. S. Fullarton ${ }^{1)}$
}

(Received $18^{\text {th }}$ July 2007)

\begin{abstract}
Differences in height-diameter (H-DBH) relationship were investigated using the Chapman-Richards function among jack pine seedlots planted in a realized genetic gain test in New Brunswick. Three seedlots representing the bulk mixed cone collection from the 1979 J.D. Irving's first-generation seedling seed orchard (JDISSO) before rogueing (UNR), after the first time genetic rogueing (1STR) and after the second time genetic rogueing (2NDR), respectively, were planted in the test. Unimproved commercial seedlots (UC) were also included for comparison. Results indicate that an overall H-DBH relationship for all the seedlots was not appropriate. Seedlot pairwise comparisons in H-DBH relationships showed that, whereas most seedlot pairs were significantly different from each other, there was no significant difference between the UNR and UC and between the 1STR and 2NDR. Two models were developed with one targeting the UNR and UC (UNIMPROVED) and the other targeting the 1STR and 2NDR (IMPROVED). The difference between the UNIMPROVED and IMPROVED models was caused only by asymptote of the Chapman-Richards function. Applying the UNIMPROVED or IMPROVED model to predict height of the 1STR and 2NDR or the UNR and UC would result in an under-estimated or an over-estimated bias by 2 to $3 \%$ in height. In light of this study, seedlot differences in $\mathrm{H}-\mathrm{DBH}$ relationships should be integrated into growth and yield models by a multiplier for height depending on genetic improvement levels.
\end{abstract}

Key words: Pinus banksiana, tree improvement, realized gain test, Chapman-Richards function, extra sum of squares method, growth and yield.

\section{Introduction}

Jack pine (Pinus banksiana Lamb.), the most widely distributed pine species in Canada, is an important source of pulpwood, lumber, and round timber. Due to its economic importance and abundant genetic variation (VAN NIEJENHUIS and PARKER, 1996; WENG et al., 2007), genetic improvement programs for this species started in the late 1970s in New Brunswick (NB) with a "seedling seed orchard" approach (FowLER, 1986; SimPSON and KATHY, 1997). Plus tree selections were made in wild stands, based on individual phenotype followed by the planting of seedling seed orchards and family tests. The genetic quality of the orchards was improved through genetic rogueing based on evaluation of their associated family tests.

Currently, seed orchard approaches are the main deployment system for improved materials in eastern Canada (FowLER, 1986). For jack pine in NB, the first-generation seedling seed orchards started to provide seed for reforestation in the mid-

\footnotetext{
1) New Brunswick Dept. of Nat. Resources, Kingsclear Forest Nursery, Island View, NB, Canada, E3E $1 \mathrm{G} 3$.

2) Faculty of Forestry and Environmental Management, 28 Dineen Drive, University of New Brunswick, Fredericton, NB, E3B 6C2.

3) J.D. Irving, Limited, Sussex Tree Nursery, 181 Aiton Rd, Sussex East, N.B., Canada, E4E 2V5.

*) Contact: Yuhui Weng, Ph.D Candidate. Telephone 506-444-5125. Fax 506-444-4917. E-Mail: Yuhui.Weng@gnb.ca
}

1980's, and have been providing virtually all stock for plantations since the early 1990's (SimPSON and KATHY, 1997). As more hectares are planted with seed orchard stock and the resulting stands mature, there becomes an urgent need to understand and model the development of these stands so that sound management plans can be developed. Most growth and yield models including the STAMAN, the current used model in NB (New Brunswick Growth and Yield Unit, 2005), were developed based on permanent sample plots of unimproved plantations, and genetic improvement effects were not accounted for. Earlier studies are few, but strongly suggest the importance of integrating genetic variation among genetic entries (provenance, family or clone) into growth and yield models. CARSON et al. (1999) have proposed using genetic-gain multipliers to adjust existing radiata pine (Pinus radiata D. Don) growth models to predict the growth of different improved seedlots. BUFORD (1986) and BUFORD and BURKHART (1987) suggested that seed source differences in loblolly pine (Pinus taeda L.) should be integrated into growth and yield models.

One of the most important components in many growth and yield models is H-DBH relationships. As tree diameters can be easily measured with higher accuracy than height in the field, $\mathrm{H}-\mathrm{DBH}$ relationships are commonly integrated into many growth and yield models to predict the mean height for a given diameter or diameter class. The diameter and predicted height values, together with stand density and survival, are then used in stand volume calculations. While investigation on $\mathrm{H}-\mathrm{DBH}$ relationships is not new for conifer species, published H-DBH relationships for jack pine are few, despite its economic importance. Peng et al. (2001) evaluated 25 non-linear H-DBH models for nine major tree species in Ontario and found that the Chapman-Richards function was the best non-linear model for jack pine. Following that, the Chapman-Richards function has been used to model H-DBH relationships in jack pine in different ecological zones (ZHANG et al., 2002; SHARMA and ZHANG, 2004).

The wide use of $\mathrm{H}-\mathrm{DBH}$ relationships dictated this investigation. Literature review indicates that genetic improvement effects on $\mathrm{H}-\mathrm{DBH}$ relationships have never been investigated, mainly due to limited available data. A test for this purpose, which serves not only to evaluate genetic performances but also to predict growth and yield, has to meet the following requirements: 1) seedlots must be collected and managed to reflect deployment strategies, 2) improved and unimproved seedlots must be planted in paired environments small enough to minimize environmental effects yet large enough to reflect stand dynamics, and 3) timing of test assessment must permit interpretation of $\mathrm{H}-\mathrm{DBH}$ relationships with reasonable confidence. While height and diameter data at different ages are readily available in many genetic tests (e.g., progeny tests) and can be used to develop H-DBH models, inferences of these models are limited due to the bias from real operational plantations (e.g., small and pure genotype plot and resulting unknown effects of intergenotypic competition). In the last 20 years, realized gain tests of large rectangular plots have been planted to demonstrate the efficiencies of tree improvement efforts 
(Elbridge, 1982; CARSON et al., 1999; Vergara et al., 2004; New Brunswick Tree Improvement Council (NBTIC), 1991), and data from these tests are ideal for development of $\mathrm{H}-\mathrm{DBH}$ equations. The objective of this study was to develop and compare equations for $\mathrm{H}-\mathrm{DBH}$ relationships applicable to seed orchard seedlots of different improvement levels using the 15year old data of a jack pine realized gain test established in NB. The consequences of applying inappropriate H-DBH models to predict seedlots of various genetic improvement levels were also evaluated.

\section{Material and Methods \\ Data}

The data for this study was collected from a jack pine realized gain test on four locations in NB (NBTIC 1991). The test was established in 1991 to measure the realized gains from planting seedlots collected from a jack pine seedling seed orchard owned by J.D. Irving Limited. (JDISSO), which was established in 1979 at Dubee Settlement. Originally, 189 families phenotypically selected from wild stands were planted in the JDISSO. The JDISSO was genetically rogued for the first time during the spring of 1986 (before pollen shed) based on an index of seven-year height and stem straightness and approximately $40 \%$ of the original families were removed (ADAMS and MoRgenstern, 1991). The orchard was rogued a second time during the spring of 1989 based on a index of maximizing the 10-year volume but keeping stem straightness and branch characteristics at the population level and $50 \%$ of the remaining families or $69 \%$ of the original families were removed (PARK et al., 1989). Three orchard seedlots, UNR, 1STR and 2NDR, representing samples from bulk mixed cone collection from the JDISSO before rogueing, following the first rogueing, and following the second rogueing, respectively, were planted at each location. Genetically, these seedlots belong to the same generation but represent different genetic improvement levels. Two unimproved stand seedlots were included and their average was used to represent unimproved commercial seedlots (UC). The average of these two stand seedlots was believed to be a good indicator of average performance of former UC for plantations in NB (NBTIC 1979).

At each location, the seedlings were planted in a randomized complete block (RCB) design with 4 blocks. Each seedlot plot contained 64 trees on a $2 \times 2 \mathrm{~m}$ spacing. The height $(\mathrm{H}(\mathrm{m}))$ and diameter at breast height $(\mathrm{DBH}(\mathrm{cm}))$ of the inner 36 trees per plot were measured at age 15 after planting. Individual tree volume $\left(\mathrm{VOL}\left(\mathrm{m}^{3}\right)\right)$ was calculated using the method described by Honer et al. (1983).

\section{Methods}

The Chapman-Richards function was selected in this study. The Chapman-Richards function can be expressed as:

$$
H=1.3+a\left(\mathrm{I}-e^{A . n B H}\right)^{\prime \prime}+\mathrm{E}
$$

where $a$ is the asymptotic or maximum height, $b$ is the rate parameter, $c$ is the shape parameter, and $\varepsilon$ is the random error. The rate parameter determines how rapidly the asymptotic height is approached, whereas the shape parameter determines the degree of curve. The Chapman-Richards function (Eq.[1]) was preliminarily fitted to data for each seedlot. The models consistently explained more than $90 \%$ of the total variation. Examination of residual plots (predicted $\mathrm{H}$ vs observed $\mathrm{H}$, residuals vs predicted $\mathrm{H}$ ) showed no evidence to indicate that the Chapman-Richards function was inappropriate for these data (results not shown). The appropriateness of the Chapman-Richards function for modeling H-DBH relationships in jack pine has previously been confirmed (PENG et al., 2001; ZHANG et al., 2002). The PROC NLIN procedure in the Statistical Analysis System (SAS Institute, Inc. 1989) was utilized to estimate the model parameters and model statistics.

To compare the H-DBH relationships among the seedlots, the non-linear extra sum of squares method was used (NETER et al., 1996). The method requires the fitting of full and reduced models. The full model corresponds to different sets of parameters for each of the seedlots, while the reduced model corresponds to the same set of parameters for all seedlots. Dummy variables were used to facilitate the hypothesis tests. Preliminary tests suggested that location effects on the H-DBH relationships were significant $(\operatorname{Pr}<0.01)$, but only explained less than $1 \%$ of the total variation (Results not shown). Thus, the effects of location were not considered and data across locations were combined in analyses. The four questions of primary interest among seedlots were:

1. Is it appropriate to use an OVERALL H-DBH relationship for all the four seedlots?

2. If an OVERALL relationship is not appropriate, is there a significant difference in the $\mathrm{H}-\mathrm{DBH}$ relationship between pairwise seedlots, especially between the UC and others?

3. If the model differences among the four seedlots or between pairwise seedlots are significant, are there any significant seedlot effects on each parameter when assumed the others are constant? and

4. If the model differences among the four seedlots or between pairwise seedlots are significant, what is the bias when an "inappropriate" model is applied to predict the height for each seedlot?

In order to examine question 1, Eq.[1] was expanded to the following full model:

$$
H=1.3+\sum_{i=1}^{4} a_{i} Z_{i}\left(1-e^{1 \sum_{i 1}^{4} h_{1} \cdot O B H}\right)^{i} r_{i}
$$

where $Z_{\mathrm{i}}=1$ if the seedlot is $i(i=1,2,3,4)$ and zero otherwise. This model has 12 estimable parameters. The reduced model for this test takes the form of Eq.[1] with 3 parameters. The null and alternative hypotheses are

$$
\mathrm{H}_{0}(1): \mathrm{a}_{1}=\mathrm{a}_{2}=\mathrm{a}_{3}=\mathrm{a}_{4}, \mathrm{~b}_{1}=\mathrm{b}_{2}=\mathrm{b}_{3}=\mathrm{b}_{4}, \mathrm{c}_{1}=\mathrm{c}_{2}=\mathrm{c}_{3}=\mathrm{c}_{4}
$$

$\mathrm{H}_{\mathrm{a}}$ (1): at least one of the equation is different from the rest.

Rejecting $\mathrm{H}_{0}(1)$ would indicate that at least one separate model is required for at least one of the seedlots, and suggest a requirement to further compare the differences between pairwise seedlots (question 2).

To test question 2, a total of 6 pairs can be formulated. The 6 testing pairs require 6 full models that take the form of Eq.[2], and 6 reduced models that take the form Eq.[1]. For example, to compare the $2 \mathrm{NDR}$ and $\mathrm{UC}, Z_{1}=1$ if seedlot is the $2 \mathrm{NDR}$ and zero otherwise, and $Z_{2}=1$ if seedlot is the UC and zero otherwise. The null and alternative hypotheses are:

$$
\mathrm{H}_{0}(2): \mathrm{a}_{1}=\mathrm{a}_{2}, \mathrm{~b}_{1}=\mathrm{b}_{2}, \mathrm{c}_{1}=\mathrm{c}_{2}
$$

$\mathrm{H}_{\mathrm{a}}(2)$ : at least one of the equation is different from the rest.

Rejecting $\mathrm{H}_{0}(2)$ would suggest different models should be developed for each seedlot, and failing to reject $\mathrm{H}_{0}(2)$ would indicate that the model from combined data is sufficient for these two seedlots.

It is also interesting and valuable to test the seedlot effects on each curve parameter (question 3 ). To test this hypothesis, a dummy variable would be used for the tested parameter only. A total of 3 full models can be formulated with each having 6 or 4 estimable parameters depending on the seedlots involved. For example, for testing the effects of the four seedlots on asymp- 
tote (a), Eq.[1] was expanded to the following full model with 6 parameters:

$$
H=1,3+\sum_{i}^{1} a_{i} Z_{i}\left(1-e^{[B H H}\right)^{*}
$$

The reduced model, again, takes the form of Eq.[1] with three 3 parameters. The null and alternative hypotheses are:

$\mathrm{H}_{0}(3)$ : all $\mathrm{a}_{\mathrm{i}}$ or $\mathrm{b}_{\mathrm{i}}$ or $\mathrm{c}_{\mathrm{i}}$ are equal $(\mathrm{i}=1,2,3,4$ or $\mathrm{i}=1,2)$

$\mathrm{H}_{\mathrm{a}}(3)$ : at least one of the $a_{i}$ or $b_{i}$ or $c_{i}$ is not equal.

Rejecting the $\mathrm{H}_{0}(3)$ would indicate that there is a difference in asymptote, rate or shape among or between the seedlots.

The approximate test statistic for the above tests is an Ftest:

$$
F=\left(\frac{\operatorname{SSE}(R)-\operatorname{SSE}(F)}{\operatorname{SSE}(F)}\right)\left(\frac{d f(F)}{d f(R)-d f(F)}\right)
$$

where $S S E(R)$ and $S S E(F)$ are the error sum of squares of the reduced and full models, respectively. $d f(R)$ and $d f(F)$ are the degree of freedoms of the error term in the reduced and full model, respectively. The p-value was calculated using the PROBF function in SAS (SAS Institute Inc., 1989) using parameters of the calculated $F$-value and degree freedom of $(d f(R)-d f(F), d f(F))$. Comparisons for a parameter difference between two models (equations) were done by calculating the confidence interval of the difference; if the interval does not include zero, then the difference of this parameter is significant at $\alpha=0.05$ level.

In order to understand the consequences of applying an "inappropriate" H-DBH relationship to each seedlot, the model that was approximate for one seedlot or seedlot group was applied to predict total tree height for the four seedlots. The prediction bias from applying an "inappropriate" H-DBH model is defined as:

$$
\text { Bias }=\left(\left(\sum_{i=1}^{k} H_{i}-\hat{H}_{j}\right) / n\right) / \bar{H} * 100
$$

where $H_{i}$ and $\hat{H}_{i}$ are the observed and predicted height of the $i^{\text {th }}$ tree, $i=1,2, \ldots, n$, and $n$ is the number of observations in the relevant seedlot. A positive bias indicates under-estimated, whereas a negative bias indicates over-estimated tree height.

\section{Results and Discussion}

Average $\mathrm{H}, \mathrm{DBH}$ and VOL at age 15 ranged from 6.95 to $7.21 \mathrm{~m}$, from 10.27 to $10.55 \mathrm{~cm}$, and from 0.0030 to $0.0033 \mathrm{~m}^{3}$, respectively, across the 4 seedlots (Table 1). These growth statistics indicate a general good growth for these jack pine plantations in NB and correspond to a site index of $18 \mathrm{~m}$ at age 50 (KER et al., 1983). Comparisons in average tree growth among seedlots indicated that there was no strong evidence of superiority of the UNR over the UC but the genetic rogueing signifi-

\begin{tabular}{|c|c|c|c|c|c|c|c|}
\hline \multirow[b]{2}{*}{ Seedlot } & \multirow[b]{2}{*}{$N$} & \multicolumn{2}{|l|}{$H(m)$} & \multicolumn{2}{|c|}{ DBH $(\operatorname{con})$} & \multicolumn{2}{|l|}{$\operatorname{VOL}\left(\mathrm{m}^{3}\right)$} \\
\hline & & Mean (STD) & Range & Mean(STD) & Range & Mean(STD) & Range \\
\hline UC & 853 & $6.95(0.82)$ & $4.10-9.10$ & $10.38(1.98)$ & $5.10-16.60$ & $0.0304(0.0126)$ & $0.0049-0.0871$ \\
\hline UNR & 457 & $6.96(0.88)$ & $3.10-9.90$ & $10.27(1.85)$ & $3.00-14.70$ & $0.0300(0.0125)$ & $0.0024-0.0660$ \\
\hline ISTR & 477 & $7.16(0.80)$ & $3.20-9.70$ & $10.47(1.85)$ & $4.40-16.20$ & $0.0317(0.0128)$ & $0.0350-0.0918$ \\
\hline 2NDR & 463 & $7.21(0.88)$ & $2.70-9.99$ & $10.55(1.89)$ & $3.90-16.00$ & $0.0325(0.0135)$ & $0.0026-0.0834$ \\
\hline Overall & 2250 & $7.05(0.85)$ & $2.70-9.99$ & $10.41(1.89)$ & $3.00-16.60$ & $0.0310(0.0128)$ & $0.0024-0.0918$ \\
\hline
\end{tabular}

Table 1. - Summary statistics of tree height (H), diameter at breast height (DBH), and volume (VOL) for the 1991 jack pine realized genetic gain test in New Brunswick.

Note: N, sample size; STD, standard deviation; Range represents the minimum and maximum observations.

Table 2. - F-tests for testing overall and parameter (asymptote, rate and shape) differ-

\begin{tabular}{|c|c|c|c|c|c|}
\hline Model & $N$ & $d f$ & SSE & $F$ & $P_{F}$ \\
\hline Reduced & 2250 & 2247 & 1037.2 & & \\
\hline OVERALL & 2250 & 2238 & 1013.9 & 5.7145 & $<0.001$ \\
\hline \multicolumn{6}{|c|}{ Tests on each parameter } \\
\hline Asymptote (a) & 2250 & 2244 & 1016.8 & 15.0017 & $<0.001$ \\
\hline Rate (b) & 2250 & 2244 & 1017.3 & 14.6321 & $<0.00 \mathrm{l}$ \\
\hline Shape (c) & 2250 & 2244 & 1018.3 & $13.883 \mathrm{l}$ & $\infty .001$ \\
\hline
\end{tabular}
ence in H-DBH relationship among the four seedlots of the 1991 jack pine realized gain test.

Note: N, sample size; $d f$, degree of freedom; $S S E$, model sum square error. 
Table 3. - F-tests for testing the differences between the paired seedlots of the 1991 jack pine realized gain test.

\begin{tabular}{|c|c|c|c|c|c|c|}
\hline \multirow[b]{2}{*}{ Scedlot pajr } & \multicolumn{2}{|c|}{ Full Model } & \multicolumn{2}{|c|}{ Reduced Model } & \multirow[b]{2}{*}{$k$} & \multirow[b]{2}{*}{$p_{r}$} \\
\hline & $d f$ & $S S E$ & $d f$ & $S S E$ & & \\
\hline UNR \&S ISTR & 928 & 403.1 & 931 & 408.7 & 4.2974 & $<0.005$ \\
\hline LNR us $2 N D R$ & 914 & 472.2 & 917 & 478.6 & 4.1293 & 0.0063 \\
\hline LNR vs UC & 1304 & 591.2 & 1307 & 594.1 & 2.1322 & 0.0940 \\
\hline 1 STR vs $2 \mathrm{NDR}$ & 934 & 422.7 & 937 & 423.7 & 0.7365 & 0.5304 \\
\hline ISTR vs UC & 1324 & 541.7 & 1327 & 553.2 & 9.3693 & $<0.001$ \\
\hline $2 \mathrm{NDR}$ YS UC & 1310 & 610.8 & 1313 & 6269 & 11.510 & $<0.001$ \\
\hline
\end{tabular}

cantly improved the growth rate of the orchard seedlots (Table 1). As expected, the $2 \mathrm{NDR}$ was the best in growth, followed by the 1STR and UNR, with a realized gain in height of 3.8, 3.1, and $0.2 \%$, respectively (NBTIC 1979).

As expected, H-DBH relationships are statistically different $(\operatorname{Pr}<0.0001)$ among the four seedlots (Table 2), suggesting the inadequacy of applying the OVERALL model to all the seedlots. The inappropriateness of the OVERALL model was associated with significant seedlot effects $(P r<0.0001)$ on both level (asymptote) and curve shape (rate and shape) (Table 2). These results suggest the necessity to further compare the differences between the pairwise seedlots, and the results are presented in Table 3. Whereas the differences in the model were significant $(P r<0.01)$ in most of the pairwise seedlots, no significant difference was found between the UC and UNR $(P r<0.094)$ and between the 1STR and 2NDR $(P r<0.5304)$. The differences in $\mathrm{H}-\mathrm{DBH}$ relationships between paired seedlots are consistent with the differences in average growth between the seedlots (Table 1) and the calculated realized gain of the orchard seedlots (NBTIC 1979). Thus, the four seedlots were grouped into two groups: UNIMPROVED representing the UC and UNR seedlots and IMPROVED representing the 1STR and 2NDR seedlots. The final H-DBH models for the UNIMPROVED (Eq.[5]) and IMPROVED (Eq.[6]) are as follows and shown in Fig. 1:

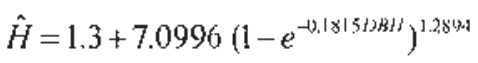

$$
\begin{aligned}
& \hat{H}=1.3+7.4248\left(1-e^{01707.15 \% H}\right)^{1.1: 1}
\end{aligned}
$$

The mean square errors (MSE) were reasonably low and comparable between the models $(0.4545$ and 0.4522 for Eqs.[5] and [6], respectively). The pseudo- $r^{2}(=1-1$-residual SS / corrected total SS) were high, 0.91 and 0.92 , respectively. The standard errors for asymptote, rate and shape were $0.2707,0.0343$ and 0.2683 for Eq.[5], and 0.3451, 0.0392, and 0.2938 for Eq.[6], respectively. The IMPROVED group had a higher level but lower rate and shape estimates than the UNIMPROVED group, suggesting that trees of the IMPROVED group of the same diameter are taller and reach maximum height slightly at higher $\mathrm{DBH}$ values than the UNIMPROVED group. The pattern of the level of the H-DBH curve directly and strongly related to the height of a specific seed source (provenance) or family was also found in loblolly pine (BUFORD and BURKHART, 1987). It can be seen from Fig. 1 that the differences between

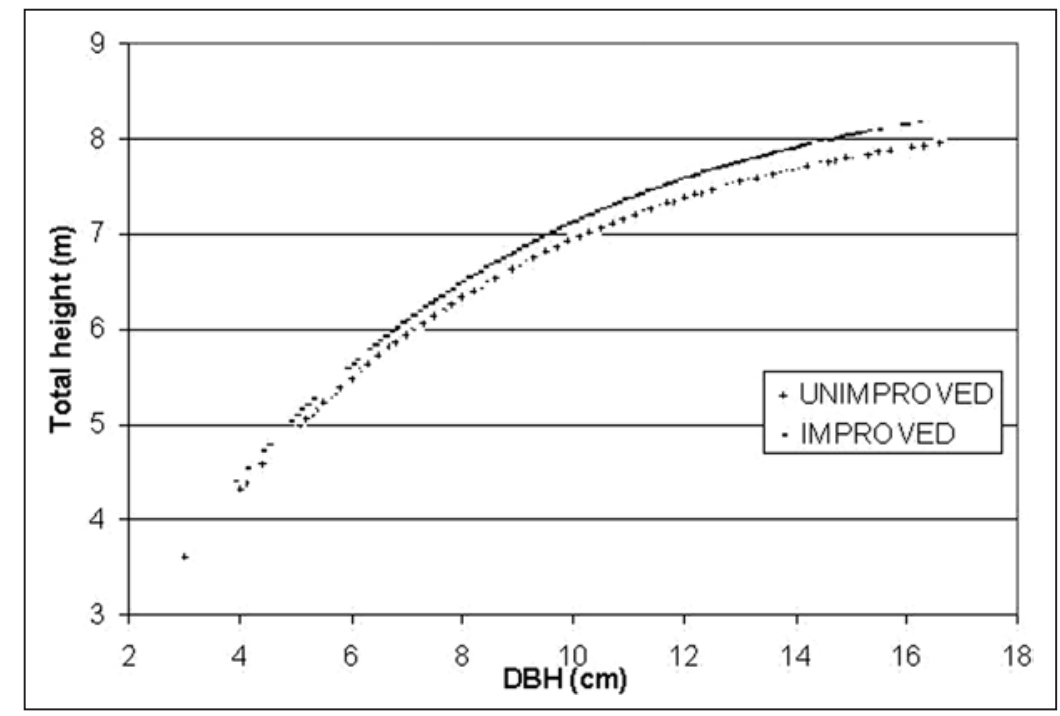

Figure 1. - Fitted height-diameter curves for the UNIMPROVED and IMPROVED seedlots of the 1991 jack pine realized gain test. 
the two curves were relatively smaller when $\mathrm{DBH}$ values were smaller but increased with the increase of $\mathrm{DBH}$ values. Further comparisons in each parameter between the two equations indicated that the difference in asymptote (the confidence interval of the difference $=0.1637 \sim 0.3613$ ) was significant at $\alpha=0.05$ level; however, after fitting different asymptotes into the respective equations, the differences in rate and shape were not statistically significant at $\alpha=0.05$ level (the confidence intervals were $-0.0203 \sim 0.0188$ and $-0.1483 \sim 0.1540$, respectively, for rate and shape), suggesting that simply adjusting asymptote, a multiplier for $\mathrm{H}$, may be sufficient for predicting height using $\mathrm{DBH}$ observations to reflect genetic improvement effects.

The growth patterns including the $\mathrm{H}-\mathrm{DBH}$ relationship of a specific seed orchard seedlot is affected not only by its genetic level (average breeding value) but also by the assumptions associated with that seed orchard, e.g., panmixis, foreign pollen contamination and others (ZOBEL and TALBERT 1984). Comparison between the predicted and realized gains has confirmed that the assumptions associated with the JDISSO were generally satisfied (NBTIC, 1979; PARK et al., 1989; ADAMs and MoRGENSTERN, 1991). The difference in H-DBH relationships may just be a consequence of the increased inter-tree competition in genetically improved seedlots, resulting in a faster growth in height. In order to remove this effect, some studies have used measurements of dominant and co-dominant trees (i.e., the tallest 100 trees per acre) to develop $\mathrm{H}-\mathrm{DBH}$ relationships (BuFORD, 1986; BuFORD and BuRKHART, 1987). Using dominant and co-dominant trees in the current study is not plausible due to relatively small number of trees per block (36 trees). Large sample size is required for non-linear model development (SAS Institute, Inc., 1989). Furthermore, for jack pine at age 15 years in NB, although tree-to tree competition has been well developed, its effect on height growth may be negligible. This was confirmed by the good normal distribution of the 15-year height for the improved seedlots (NBTIC, 1991). Thus, the differences in the level of the model revealed in this study are mainly a result of genetic improvement levels. Results in this study suggest that the genetic improvement effects on $\mathrm{H}-\mathrm{DBH}$ models are complicated; its effects may be involved with the level of H-DBH relationships and determined by actual genetic improvement levels. People may think, compared to unimproved commercial seedlots, that trees of improved stock can grow significantly faster and consequently, show a different $\mathrm{H}$ DBH relationship. In light of this study, this may not be true for seedlots collected from unrogued first-generation seed orchards. This is not surprising considering the fact that the unrogued orchards consisted of large number of phenotypic selected plus-trees. The low heritabilities for growth traits in jack pine (RIEMENSCHNEIDER, 1988; MoRRIS et al., 1992; WENG et al., 2007) make these phenotypic selections less efficient. Genetic rogueing of a seed orchard involves removing "genetically" poor individuals based on results from family or progeny tests so that the growth of the orchard seedlot is improved, resulting in a significant change of the level, but not the shape of the H-DBH relationship, as indicated in this study. However, compared to the 1STR, although the $2^{\mathrm{ND}}$ time genetic rogueing further improved the growth (Table 1), the improvement is not large enough to make a significant change in the level of the $\mathrm{H}$ DBH relationship.

Reported H-DBH models accounting for genetic improvement levels were few. Based on a logarithmic model, BUFond (1986) and BUFFORD and BURKHART (1987) found that the shape of $\mathrm{H}$ DBH relationship did not differ among families or provenances of loblolly pine, but the level did. KNOWE et al. (1998) compared H-DBH relationships among seven eastern cottonwood (Populus deltoids Bartr.) clones planted as both monocultures and mixtures and found that the effects of the clonal proportion, although statistically significant, were not important enough to incorporate into the final H-DBH model. However, the unknown intergenotypic competition within small and pure genotype plots in the above cited studies may bias the H-DBH relationship. In line with the results of the current study, in a test with large block plot design for Douglas-fir programs that selected primarily on height, JoHNSON (2002) suggested growth multipliers for height and not DBH to adjust tree improvement

Table 4. - Summary statistics and predicted biases of applying the UNIMPROVED and IMPROVED models to each seedlot of the 1991 jack pine realized gain test.

\begin{tabular}{llllll}
\hline Model & Variable & UC & UNR & 1 STR & 2NJR \\
& & & & & \\
\hline & $H(\mathrm{~m})$ & 6.9477 & 6.9642 & 7.1625 & 7.2084 \\
& $\bar{V}$ & 3.0399 & 3.0003 & 3.1744 & 3.2463 \\
Unimproved & $\hat{H}(\mathrm{~m})$ & 6.9694 & 6.9293 & 6.9895 & 7.0059 \\
& Bias $(\%)$ & -0.31 & 0.57 & 2.42 & 2.81 \\
& $\hat{V}$ & 3.0488 & 2.9905 & 3.1019 & 3.1624 \\
& Bias $(\%)$ & -0.29 & 0.33 & 2.28 & 2.58 \\
Improved & $\hat{H}(\mathrm{~m})$ & 7.1519 & 7.1060 & 7.1729 & 7.1901 \\
& Bias $(\%)$ & -2.94 & -2.03 & -0.14 & 0.25 \\
& $\hat{V}$ & 3.1248 & 3.0650 & 3.1794 & 3.2416 \\
& Bias $(\%)$ & -2.83 & -2.20 & 0.19 & 0.11 \\
& & & & &
\end{tabular}

Note: $\bar{H}$, average of observed tree height, $\hat{H}$, average of predicted tree height, $\bar{V}$, average tree volume calculated using tree height, $\hat{V}$, average tree volume calculated using predicted tree height. 
effects on growth. However, CARSON et al. (1999) compared growth models for varying genetic quality for Pinus radiata, a program with selection primarily on $\mathrm{DBH}$, suggested to incorporate a "growth gain multiplier" for DBH to predict growth of genetically improved seedlots. These results suggest that the adjustments to an H-DBH equation might be a function of how the population was selected, and this may partly explain the insignificant difference between the 1STR and 2NDR as they had different selection targets, i.e., height for the 1STR but volume for the 2NDR. Despite the differences, however, these studies suggest that H-DBH models may need to account for specific differences in improvement levels or genetic entries.

According to the tests above, there were significant differences between the seedlots in the level of the H-DBH models. Inappropriately "applying" an $\mathrm{H}-\mathrm{DBH}$ model in these seedlots may result in prediction biases. To understand the consequences, the Eq.[5] and Eq.[6] were used to predict total tree height for each seedlot, and the prediction biases are shown in Table 4. As expected, the biases were small when the Eq.[5] was used to predict the tree height for the UC and UNR or Eq.[6] to predict the tree height for the 1STR and 2NDR. If the UNIMPROVED model (Eq.[5]) was used to predict the tree height of each seedlot, the model under-estimated tree heights by 2.28 and $2.58 \%$, respectively, for the 1 STR and 2 NDR. When the IMPROVED model (Eq.[6]) was applied to predict tree height, the model over-estimated tree heights of 2.03 to $2.94 \%$ for the UC and UNR seedlots. Individual tree volume showed very similar patterns and magnitudes in biases as those for height from applying inappropriate models. These biases in individual trees may reflect significant differences in stand dynamics and yield. Therefore, differences in H-DBH relationships should be recognized even though biases in predicted height are relatively small.

Results in this study can be used to incorporate genetic improvement effects into growth and yield modeling, where heights are predicted using $\mathrm{DBH}$, and then used to predict volume together with other variables. Eq.[5] may be applied to jack pine plantations established using seedlots collected from unrogued first generation orchards or unimproved commercial stands, and the Eq.[6] should be applied to plantations of the rogued seed orchard seedlots in NB. The results in the current study may also provide some implications in growth prediction for jack pine plantations in other regions, e.g., Ontario (DENNIS and NiTSCHKE, 1993) and other Atlantic provinces (FowLER, 1986), where a similar breeding strategy for this species was applied.

Caution should be taken when the results in this study are applied to plan forest management. Most important, there are no available independent data sets to validate these models. The seedlots used in this study only represent the improvement levels of the JDISSO. The genetic quality of seed orchards could differ greatly from one to another (ZOBEL and TALBERT, 1984). Also, the test was planted at one stand density and $\mathrm{H}-\mathrm{DBH}$ relationships may vary with planting density. For jack pine in NB, age 15 is one-third of its rotation age and $\mathrm{H}$ DBH relationships may change as the trees in the test plantations become larger. The tests should be maintained and measured so that these early relationships can be confirmed. When data older than 30 years is available, differences between the seedlots in other important growth functions, i.e., survival-age, $\mathrm{H}$-age (site index), and DBH distributions should be investigated. Only then can a general picture of tree improvement effects on growth and yield be formed. However, as the first report in this topic, results in this study indicate that, compared to unimproved sources, tree improvement levels may change the level of the $\mathrm{H}-\mathrm{DBH}$ relationship. Thus, a multiplier for $\mathrm{H}$ (2 3\% in this case) should be incorporated into the current practice of using models based on unimproved permanent sample plots to predict the plantations of improved seedlots from this seed orchard.

\section{Conclusions}

Results presented here suggest that the seedlots of different genetic levels play an important role in the asymptote of $\mathrm{H}$ DBH relationships. The seedlot effects, as expected, are also affected by actual improved levels; no significant differences exist in H-DBH models between the UC and UNR, and between the 1STR and 2NDR. The inappropriate application of models can produce $2 \sim 3 \%$ biases for estimating total tree height of seedlots of different genetic levels. Incorporating a multiplier for $\mathrm{H}$ into the current model based on unimproved seedlots may provide more accurate predictions for tree heights and subsequently, volume, of the plantations of improved seedlots.

\section{Reference cited}

AdAms, G. W. and E. K. Morgenstern (1991): Multiple-trait selection in jack pine. Canadian Journal of Forest Research 21: 439-445.

BuFoRD, M. A. (1986): Height-diameter relationships at age 15 in loblolly pine seed sources. Forest Science 32: 812-818.

Buford, M. A. and H. E. BurKhaRT (1987): Genetic improvement effects on growth and yield of loblolly pine plantations. Forest Science 33: 707-724.

Carson, S. D., O. Garcia and J. D. HaYes (1999): Realized gain and prediction of yield with genetically improved Pinus radiata in New Zealand. Forest Science 45: 186-200.

DenNis, J. and P. NitschKe (1993): An advanced generation breeding strategy for jack pine in Ontario. In: Breeding Strategies of Important Tree Species in Canada. 1993. Edited by Y. S. PARK and G. W. ADAMS. Information Report M-X186E, Natural Resource Canadian, Maritime Forestry Research Centre, Fredericton, New Brunswick.

ElBRIDGE, K. E (1982): Genetic improvement from a radiate pine seed orchard. New Zealand Journal of Forest Science 12: 404-411.

FowleR, D. P. (1986): Strategies for the genetic improvement of important tree species in the Maritimes. Information Report M-X-156, Canadian Forest Service, Maritime Forestry Research Centre, Fredericton, New Brunswick.

Honer, T. G., M. F. KeR and I. S. Alemdag (1983): Metric timber tables for the commercial tree species of central and eastern Canada. Information Report M-X-140, Canadian Forest Service, Maritime Forestry Research Centre, Fredericton, New Brunswick.

JoHNSON, G. (2002): Modelling the effects of genetic improvement on diameter and height growth. http://westernforestry. org/wmens/m2002/gpjohnson.ppt (accessed Dec. 18, 2007).

KeR, M. F., S. A. Roland and J. F. Coles (1983): Site-index curves for black spruce, white spruce, jack pine and tamarack in New Brunswick. New Brunswick Department of Natural Resources, Fredericton, New Brunswick. 12p.

Knowe, S. A., G. S., Foster, R. J. Rousseau and W. L. Nance (1998): Height-age and height-diameter relationships for monocultures and mixtures of eastern cottonwood clones. Forest Ecology and Management 106: 115-123.

Knowe, S. A. and G. S. FOSTER (1989): Application of growth models for simulating genetic gain of loblolly pine. Forest Science 35: 211-228.

Morris, D. M., Parker, W. H. and R. Seabrook (1992): Some considerations when selecting young jack pine families using growth and form traits. Canadian Journal of Forestry Research 22: 429-435. 
Neter, J., M. H., KutNer, C. J. NAChtSheim and W. WAsSerman (1996): Applied Linear Statistical Models, $4^{\text {th }}$ ed. Times Mirror Higher Education Group, Inc. Iwin, Chicago, IL.

New Brunswick Growth and Yield Unit (NBGYU) (2005): STAMAN v.5.5.1. user manual. New Brunswick Growth \& Yield Unit. Fredericton, New Brunswick. 31p.

New Brunswick Tree Improvement Council (NBTIC) (1976) 1976 jack pine stand tests. Fredericton, New Brunswick.

NBTIC (1979): 1979 jack pine seedling seed orchards and family tests. Fredericton, New Brunswick.

NBTIC (1991): 1991 jack pine realized gain test. Est. Rep. No. 35. Fredericton, New Brunswick.

PARK, Y. S., J. D. Simpson, D. F. Fowler and E. K. MorgenSTERN (1989): A selection index with desired gains to rogue jack pine seedling seed orchards. Information Report M-X176, Forestry Canada - Martimes Region, Fredericton, New Brunswick.

Peng, C. H., L. Zhang and J. LiU (2001): Developing and validating nonlinear $\mathrm{H}-\mathrm{DBH}$ models for major tree species of Ontario's boreal forests. Northern Journal of Applied Forestry 18: 87-94.

RIEMENSCHNEIDER, D. E. (1988): Heritability, age-age correlations, and inference regarding juvenile selection in jack pine. Forest Science 34: 1076-1082.

SAS Institute Inc. (1989): SAS/STAT user's guide, version 6, fourth Edition, volume 2, Cary, NC. 846p.
SHARMA, M. and S. Y. ZHANG (2004): Height-diameter models using stand characteristics for Pinus banksiana and Picea mariana. Scandinavian Journal of Forest Research 19: $442-451$.

Simpson, D. and K. Tosh (1997): The New Brunswick Tree Improvement Council is 20 years old. The Forestry Chronicle 73: 572-577.

van Niejenhuis, A. and W. H. PARKer (1996): Adaptive variation of jack pine from north central Ontario determined by short-term common garden tests. Canadian Journal of Forest Research 26: 2006-2014.

Vergara, R., T. L. White, D. A. Huber, B. D. Shiver and D. L. RocKWOOD (2004): Estimated realized gains for first-generation slash pine (Pinus elliottii var elliottii) tree improvement in the Southeastern United States. Canadian Journal of Forest Research 34: 2587-2600.

Weng, Y. H., K. J. Tosh, Y. S. Park and M. S. Fullarton (2007): Age-related trends in genetic parameters for jack pine and their implications for early selection. Silvae Genetica. 56: $242-252$.

ZoBEL, B. and J. TALBERT (1984): Applied forest tree improvement. John Wiley \& Sons, Inc. New York, U.S.

Zhang, L. J., C. H. Peng, S. M. Huang and X. L. Zhou (2002): Development and evaluation of ecoregion-based jack pine $\mathrm{H}-\mathrm{DBH}$ models for Ontario. The Forestry Chronicle 78: $530-538$.

\title{
A Strategy for the Second Breeding Cycle of Larix $\mathbf{x}$ marschlinsii in Québec, Canada Including Experiments to Guide Interspecific Tree Breeding Programme
}

\author{
By M. PERRON ${ }^{1)}$
}

(Received 23 $3^{\text {rd }}$ July 2007)

\begin{abstract}
A strategy for the genetic improvement of Larix decidua P. Mill., L. kaempferi (Lamb.) Carrière and their hybrid (L. x marschlinsii Coaz) in Québec, Canada, was set up to provide short and long-term genetic gains, as well as basic populations for some fundamental experiments. A reciprocal recurrent selection with forward selection strategy (RRS-FS) will be applied by using a pollen mix breeding with a partial population paternity analysis (PMX/WPPA). The genetic mechanisms responsible for heterosis among trees remain poorly understood. This complicates the implementation of multi-species genetic improvement programmes seeking to achieve the full benefits of interspecific hybridization. Various strategies to exploit heterosis are outlined. To expand our knowledge and guide our future choices, basic research has been integrated

\footnotetext{
1) Martin Perron. Direction de la recherche forestière, ministère des Ressources naturelles et de la Faune du Québec (MRNF) 2700, rue Einstein, Québec (Québec), Canada G1P 3W8. Telephone: (418) 6437994 \#6547, Fax: (418) 643-2165. E-Mail: martin.perron@mrnf.gouv. qc.ca
}

directly into breeding and testing activities, as well as through experiments integrated within activities leading to recommendations about the top-ranked families to be used in reforestation (cuttings). These experiments can also serve as the basis for future studies seeking a better understanding of heterosis through molecular genetics.

Key words: paternity analysis, heterosis, interspecies hybrid, interspecific breeding strategy, polymix crossing, Larix x eurolepis.

\section{Introduction}

After more than 30 years of testing introduced larches, the Ministère des Ressources naturelles et de la Faune du Québec (MRNF-Q; Québec Ministry of Natural Resources and Wildlife) has passed an important milestone with respect to intensive silviculture in Québec. Effectively, we have decided to progress toward a second breeding cycle of Larix x marschlinsii (Coaz), notably because this larch variety has been identified as the most productive in Québec commercial forests (STIPANICIC, 1999). This variety of hybrid between European larch (EL; 